\title{
A randomized comparison of supervised clinical exercise versus a home exercise program in patients with chronic low back pain
}

\author{
Tarek Ammar* \\ *Correspondence: tarekphysical@yahoo.com

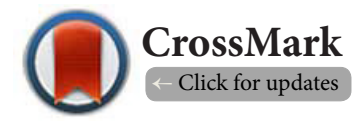

Assistant Professor, Faculty of Physical Therapy, Cairo University, Cairo, Egypt.

\begin{abstract}
Objective: The purpose of this study was to compare between the effects of clinically supervised exercises and HEP on pain, disability and physical function in patients with chronic low back pain (LBP).

Setting: A physical therapy outpatient clinic.

Participants: Thirty-three participants with chronic LBP completed the program. Pain duration was more than 12 weeks.

Interventions: The first group $(n=17$, mean age $=41.5 \pm 13.5$ years $)$ received clinically supervised exercises and HEP. The second group $(\mathrm{n}=16$, mean age $=44.2 \pm 15.6$ years $)$ received HEP.

Materials: Visual analogue scale, Oswestry disability questionnaire and performance based measures (the fifty-foot preferred speed walk, fifty-foot fast walk, and distance walked in five minutes) were used to measure pain, disability and physical function before and after 6 weeks of intervention.

$\underline{\text { Results: }}$ Analysis of covariance tests revealed statistically significant decrease in pain, $\left(\mathrm{F}_{1.30}=5.46, \mathrm{P}=0.01\right)$ and disability $\left(\mathrm{F}_{1.30}=6.4, \mathrm{P}=0.01\right)$ in the first group. They also showed increase in physical function as measured by the fifty-foot preferred speed walk $\left(\mathrm{F}_{1.30}=6.9, \mathrm{P}=.01\right)$, fifty-foot fast speed walk $\left(\mathrm{F}_{1.30}=7.5\right.$, $\mathrm{P}=0.001)$, and distance walked in five minutes $\left(\mathrm{F}_{1.30}=9.5, \mathrm{P}=0.01\right)$ in the first group.

Conclusion: Supervised exercises improved all dependent parameters better than HEP alone in patients with chronic LBP. In this study, clinically supervised exercises are better than HEP alone in patients with nonspecific chronic LBP.
\end{abstract}

Keywords: Low back pain, home program, exercise, supervised

\section{Introduction}

Low back pain (LBP) is defined as lumbosacral pain originating between the bottom of the twelfth rib and above the gluteal fold [1]. LBP is the most common cause of disability in people aged 45-65 [2]. It is also a socio-economic problem since LBP frequently causes workforce absenteeism [2,3]. LBP is considered chronic when it lasts longer than three months [4,5]. 15-45\% of the population may get chronic LBP [5].

Exercises are commonly used to manage patients with chronic LBP [6-8]. Home exercise programs are practical, economic, and long-term effective intervention methods for chronic LBP, and are as effective as standard physical treatment methods, and maybe more effective in the long term $[9,10]$. Healthcare costs continue to increase worldwide. Therefore, the need for cost effectiveness emphasizes the importance of knowing whether patients requirephysical therapy supervised sessions or whether they might receive a similar benefit from a home exercise program (HEP).

It remains unclear whether supervised exercises and home programs are similarly effective or not in managing clients. A few research has been conducted about this point and there is a controversy about which method provides an additional benefit 
over the other. The purpose of this study was to determine the effectiveness of a supervised exercise program compared with a HEPfor patients with chronic LBP. The following null hypothesis was tested: no difference exists among groups of participants receiving supervised exercise versus HEPin reducing pain intensity, disability and improving physical function in patients with chronic LBP.

\section{Methods \\ Design}

Participants were randomly assigned to one of two treatment groups: (1) a group that received the clinically supervised exercises and HEP. (2) a group that received the HEP. The research physical therapist who performed the outcome assessments of participants and data analyses was unaware of group allocation. However, the clinical physical therapist who administered the exercises was aware of group allocation. Participants in group 1 received two session per week for six weeks.

\section{Participants}

Fifty-nine participants with chronic mechanical LBP were recruited from a physical therapy outpatient setting. Participants of any race or gender with a history of chronic mechanical LBP between $T 12$ and the gluteal fold for more than 12 weeks were eligible for the study.

Exclusion criteria included a history of orthopedic surgery to the back, spinal stenosis, spondylolisthesis, injection therapy, carcinoma, cardiovascular and neurological conditions.

\section{Measurements}

Visual analogue scale (VAS) was used to measure pain intensity. It is a valid and reliable scale in which 0 equals no pain and 10 equals worst possible pain [11]. The Oswestry disability questionnaire (ODQ) was used to measure disability [12]. It includes 10 sections and each section contains six statements. Each section is scored on a 0 -to- 5 scale, with higher values representing greater disability. Three performance-based measures (fifty-foot preferred speed walk, fifty-foot fast speed walk, and distance walked in five minutes) were used to measure physical function in patients with $\operatorname{LBP}[13,14]$. For the fifty-foot preferred speed walk, the patient walks forward at his/her preferred walking speed for 25 feet and turns around and returns to the starting position.For the fifty-foot fast speed walk, the patient walks as fast as possible forward for 25 feet and turns around and returns to the starting position. For the distance walked in five minutes, the therapist measures the farthest distance the patient can walk within five minutes. They have been reported as valid and reliable measuring tools in LBP $[13,14]$.

\section{Interventions}

All subjects signed a consent form permitting the use of their data for research purposes. After informed consent was obtained, the research therapist examined all participants to check for inclusion and exclusion criteria and was not aware of the intervention assignmentsHe tested the participants at both the baseline and final sessions. Another therapist performed all interventions.Each participant was randomly assigned to either a supervised exercise group (Group 1) or a HEP(Group 2), using a table of random numbers.

Participants in the first group received McGill exercises [15]. Each patient was trained to maintain the neutral spinal postureduring the performance of stabilization exercise. The program started with a cat-camel motion exercise. It consists of six-to-eight cycles of spinal flexion and extension in a quadruped position. The patient should tighten the abdominal muscles during exercise performance. Then, patient performed the curl-up exercises, in which the individual flexes one knee while keeping the other straight and gently raises just the head and shoulders a short distance off the floor. This was followed by the dead bug exercises where the subject lays on the back with the arms extended in front of the shoulders. The subject should bend hips and knees to a 90-degree angle. The patient should slowly extend the left leg toward the floor and bring the right arm overhead. The next progression is the the side-support exercise in which the subject is lying on the side supported on his/her elbow and hip, knees bent to $90^{\circ}$, free hand placed on the opposite shoulder. Then he/ she raises his/her trunk until the body is supported on the elbow and the knee. The subject was instructed to assume the side lying position and initiate an isometric contraction of the quadrates lumborum by trying to lift both lower limbs up toward the ceiling, if not able to perform the side support exercise. The last exercise was the birddog exercise (opposite arm and leg extension in the quadruped position) [15].

Participants did one set of 10 repetitions for each McGill exercise, with a 30-second to one-minute rest between each set during each exercise session. They performed two sets of 10 repetitions for each exercise, with a 30-second to oneminute rest between each set on the on the days when they did not come to the clinic as a HEP. Participants received a series of progressive exercises based upon their tolerance. Participants who were able to perform difficult stabilization exercises would not perform easy ones. For instance, participants who were able to perform the dead bug exercise would not perform individual arm or leg lifting exercises. Also, participants who were able to perform the arm and leg extensions in the quadruped position would not perform individual arm or leg extensions in the quadruped position.

Participants in the second group received a HEP. The treating physical therapist provided one educational treatment session. Participants in Group 2 performed four to six McGill exercises (the cat-camel motion, one or two exercises to recruit the abdominals such as the curl-up, arm lifting, leg lifting, and dead bug exercises, the horizontal side support exercise, and one or two of the quadruped exercises to recruit the spinal extensors). They performed two sets of 10 repetitions for each 
exercise, with a 30-second to one-minute rest between each set per day. In both groups, the therapist asked the participants to use weekly self-report exercise logs to monitor exercise adherence. The treating therapist asked the participants to call if they had any question. The therapist provided them with self-report logs to mark each of their prescribed exercises.

The therapist conducting the treatment also provided the following instructions to participants in both groups: 1 ) avoid prolonged bed rest beyond the usual eight hours of sleep, 2) avoid prolonged sitting and spine twisting, and 3) utilize proper body mechanics during lifting activities.

In addition, the HEP participants were asked to return to the clinic for control evaluations after two weeks, and were asked to re-do their exercises. Examiners checked for adverse signs and symptoms. The therapist reviewed the logs and observed the performance of the exercises to correct performance deficiencies. Exercises were progressed only if the symptoms and signs of chronic LBP were stable or decreasing.

Participants were permitted to continue taking any medications that had been initiated 30 days or more prior to enrollment in the study. Participants from both groups returned to the clinic for another blinded assessment of VAS, ODQ, and the physical function measurements after 6 weeks.

\section{Data analysis}

Data analysis was performed using SPSS for Windows, version 18.0. Separate univariate analyses of covariance with the pretest scores as the covariates, were performed to determine whether there is a difference between the two groups on the posttest scores of physical function. A Bonferroni approach was used to maintain the alpha level at $P<0.05$.

\section{Results}

Eleven patients were unwilling to participate in the study, and eight patients did not meet the inclusion criteria described above. The other 40 participants were randomly assigned to one of two groups. However, in Group 1, one patient withdrew for developing unrelated medical illness. Another one withdrew for changing pain medications during the study. Two participants missed more than two physical therapy sessions due to scheduling difficulties In Group 2, two participants missed more than two physical therapy sessions due to scheduling and transportation difficulties. Also, one participant failed to return for unknown reasons.Patient flow through the study is shown in the CONSORT flow chart shown in the Figure 1.

Group one comprised 16 participants ( 9 females and 7 males) average age $41.5 \pm 13.5$ years, height $67.2 \pm 11.2$ inches, and weight $159.2 \pm 23.2$ pounds. Group 2 comprised 17 participants ( 10 females and 7 males), average age $44.2 \pm 15.6$ years, height $70.1 \pm 9.4$ inches, and weight $165.1 \pm 22.3$ pounds.

Group one comprised 16participants ( 9 females and 7 males) average age $41.5 \pm 13.5$ years, height $69.2 \pm 10.2$ inches, and weight $157.2 \pm 21.4$ pounds. Group 2 comprised 17 participants ( 10 females and 7 males), average age $44.2 \pm 15.6$ years,

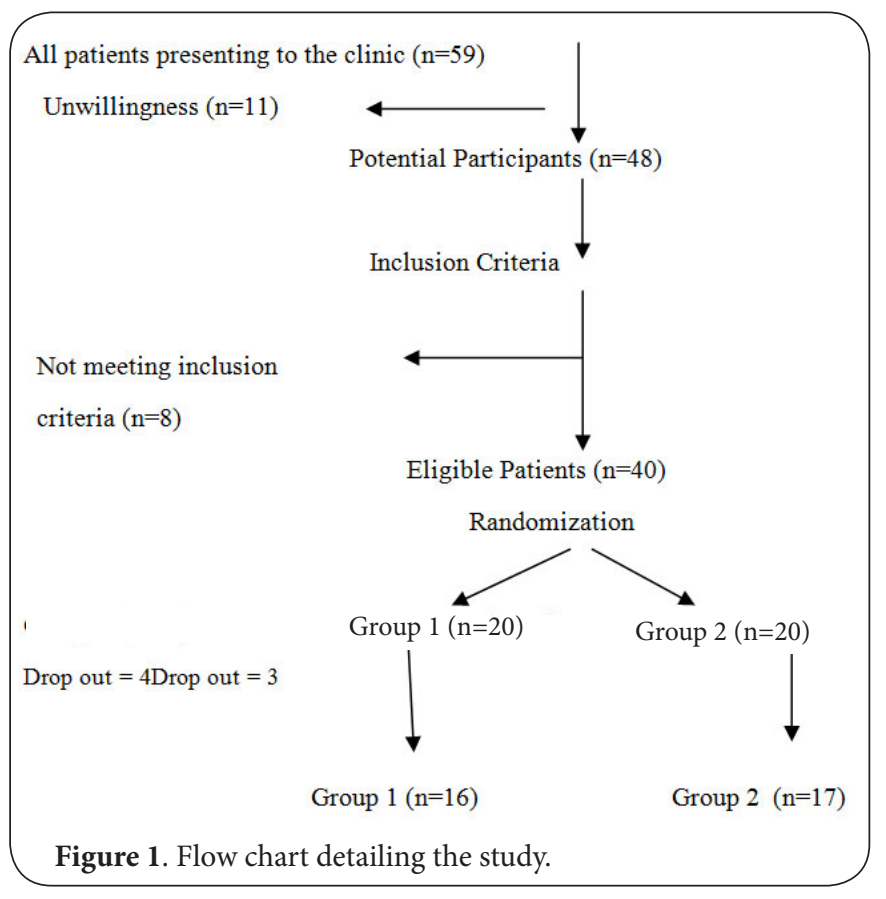

height 71.4 \pm 9.4 inches, and weight $163.1 \pm 20.2$ pounds. No adverse events were observed or reported by any participant in either intervention group. Both groups had similar age, weight, and sex characteristics.

For pain intensity, the analysis of covariance revealed a significant difference between the two groups $\left(\mathrm{F}_{1.30}=5.46, \mathrm{P}=0.01\right)$ in favor of the first group (Table 1). For disability, the analysis of covariance revealed a significant difference between the two groups $\left(F_{1.30}=6.4, P=0.01\right)$, with group 1 having a lower disability posttest mean (Table 2).

For the fifty-foot preferred speed walk, the analysis of co-

Table 1. Analysis of Covariance for the Variable of Pain Using the Pretest as the Covariate.

\begin{tabular}{lllll}
\hline & Sum of Square & Df & Mean Squares & F \\
\hline Main Effects Group & 0.822 & 1 & 0.822 & 5.46 \\
Covariate Pretest & 72.742 & 1 & 72.742 & 72.31 \\
Residual & 30.704 & 30 & 0.867 & -- \\
Total & 104.366 & 33 & 2.738 & -- \\
\hline
\end{tabular}

$\mathrm{P}=0.01$

Table 2. Analysis of Covariance for the Variable of Fifty-Foot Preferred Speed Walk Using the Pretest as the Covariate.

\begin{tabular}{lllll}
\hline & Sum of Square & Df & Mean Squares & F \\
\hline Main Effects Group & 17.463 & 1 & 17.463 & 6.4 \\
Covariate Pretest & 136.35 & 1 & 136.35 & 49.253 \\
Residual & 96.02 & 30 & 3.637 & -- \\
Total & 322.35 & 33 & 6.742 & -- \\
\hline
\end{tabular}


variance revealed a significant difference between the two groups $\left(F_{1.30}=6.9, P=0.01\right)$ in favor of the first group (Table 3 ). For the fifty-foot fast speed walk, the analysis of covariance revealed a significant difference between the two groups $\left(F_{1.30}=7.5, P=0.01\right)$ in favor of the first group (Table 4). For the distance walked in five minutes $\left(F_{1.30}=9.5, P=0.01\right)$, in favor of the first group (Table 5). The first group displayed higher mean post-test scores as measured by the three physical performance measures.

Table 3. Analysis of Covariance for the Variable of Fifty-Foot Preferred Speed Walk Using the Pretest as the Covariate.

\begin{tabular}{lllll}
\hline & Sum of Square & Df & Mean Squares & F \\
\hline Main Effects Group & 75.4 & 1 & 75.4 & 6.9 \\
Covariate Pretest & 1221.2 & 1 & 1221.2 & 94.3 \\
Residual & 562.3 & 31 & 12.4 & -- \\
Total & 10201 & 33 & 192.1 & -- \\
\hline
\end{tabular}

$\mathrm{P}=0.01$

Table 4. Analysis of Covariance for the Variable of Fifty-Foot Fast Speed Walk Using the Pretest as the Covariate.

\begin{tabular}{lllll}
\hline & Sum of Square & Df & Mean Squares & F \\
\hline Main Effects Group & 29.5 & 1 & 29.5 & 7.5 \\
Covariate Pretest & 142.1 & 1 & 142.1 & 36.2 \\
Residual & 180.66 & 31 & 4.2 & -- \\
Total & 4870 & 33 & 100.21 & -- \\
\hline $\mathrm{P}=0.01$ & & & &
\end{tabular}

Table 5. Analysis of Covariance for the Variable of Distance Walked in Five Minutes Using the Pretest as the Covariate.

\begin{tabular}{lllll}
\hline & $\begin{array}{l}\text { Sum of } \\
\text { Square }\end{array}$ & Df & Mean Squares & F \\
\hline Main Effects Group & 2453 & 1 & 2453 & 9.5 \\
Covariate Pretest & 312364.6 & 1 & 312364.6 & 1367.3 \\
Residual & 10602.1 & 31 & 216.4 & -- \\
Total & 10448320 & 33 & 197126.4 & -- \\
\hline
\end{tabular}

$\mathrm{P}=0.01$

\section{Discussion}

The purpose of this study was to compare between the effects of supervised exercises and HEP on pain, disability and physical function in patients with chronic LBP. There is a need to determine if physical therapists can rely on HEP as a viable alternativeto clinical visits to save costs, energy and time.

All participants showed decrease in pain and disability and increase in physical function in both intervention groups although the improvements were statistically significantly greater in the supervised exercise group. The logical explanation is that the supervised exercise group performed better due to poor adherence of the patients to the HEP or inaccurate performance of the exercises. Although participants were provided with careful description and brochures, they may have been performing some or all the HEPs inaccurately. This indicates the importance of supervised exercise programs.

Participants received McGill stabilization exercises in this study. McGill proposed safe stabilizing exercises to enhance spinal stability without imposing high loads on the spine in patients with LBP [15]. These exercises would achieve appropriate levels of activation of all back and abdominal muscles (rectus abdominis, quadratus lumborum, obliques, transversus abdominis, multifidus, and erector spinae), with minimal spinal loading to ensure spinal stability in patients with LBP [15]. Those exercises have been shown to reduce pain and disability in women with postnatal LBP [16]. Further, research showed that McGill exercises may increase physical function in patients with chronic nonspecific LBP [17].

The success of any supervised or HEP depends on the adherence of patients to the treatment program, and on the accurate performance of the exercises. Therefore, it was measured in this trial. Adherence is defined as the maintenance of an exercise regimen for a prolonged period of time following the initial adoption phase [18]. Poor adherence of the patients to the home programs is a major obstacle in the success of any HEP. Poor adherence affects the effectiveness, period, cost of treatment, and the statistical results of the clinical studies.

Exercise adherence is accepted as the most significant factor in the success of exercise programs; therefore, measuring exercise adherence is crucial $[19,20]$. There is no golden standard by which to measure exercise adherence, although strengthening and flexibility parameters are reported to as appropriate methods for measuring adherence [21]. Selfreport logs were used to measure exercise adherence in this study. Although they often overestimate adherence, they are commonly used methods to assess adherence [22].

The adherence rate was poor for both groups in this study. For the supervised exercise program group, the rate equaled $36.30 \pm 14.41 \%$ (minimum: $14.2 \%$, maximum: $88 \%$ ). While, it was $32.10 \pm 15.21 \%$ (minimum: $13.4 \%$, maximum: $90 \%$ ) for the HEP group. This agreed with the adherence rates reported in a few clinical studies. Adherence to home programs has not been adequately reported in many randomized controlled studies [6]. The literature reports adherence rates of $30-50 \%$ for clinically supervised exercises and $35-84 \%$ for home-based programs $[20,21]$.

The adherence to home-based exercises by patients with LBP is inadequate [6]. A study examined the adherence to home-based stabilization exercise programs of musculoskeletal patient groups [22]. The authors measured the adherence of 32 patients with LBP to the 9-week program. Adherence was documented as: percent attendance at therapy, percent adherence to daily home exercises (patient diary) and percent commitment to rehabilitation (Sports Injury Rehabilitation Adherence Scale. They used a multidimensional adherence 
index (MAl) which is the average of these three measures. They reported that adherence to home exercises showed a moderate, positive correlation with the reduction in average pain (Rho $=0.54, P=0.003$ ) and disability ( $R h o=0.38, P=0.036$ ); higher MAl scores were associated with greater reductions in average pain (Rho $=0.48, P=0.008$ ) and a non-statistical significant tendency for greater reductions in disability $(\mathrm{Rho}=0.32$, $P=0.07$ ). They postulated that benefits of exercise programs rely much on the patient's exercise behavior outside of the clinical supervised visits.

There has been a few research investigating whether clinically supervised visits provide additional benefits over home-based programs. However, there have been a wide controversy. This study findings agreed with the results of a study done in 2001 who compared between a supervised exercise program versus a HEP for walking ability and quality of life measures in patients with exercise-limiting intermittent leg claudication [23]. The authors of that studyfound that a supervised exercise program was more effective at improving the absolute exercise-limiting intermittent claudication distance over a 24-week period than a home-based program. However, they suggested that a HEP can be a safe, low-cost alternative that provides similar long-term (24 weeks) exercise benefits in intermittent leg claudication if patients are screened and properly received adequate instruction.

Few studies failed to find any differences between supervised and home based programs. For example, authors of a study demonstrated that HEP and supervised exercises were equally effective in short term improvements in physical function and knee range of motion after total knee replacement at equivalents costs for patients with after total knee replacement [24]. Their study was based on a meta-analysis that had significant statistical heterogeneity. Also, researchers of another study did a systematic review and concluded that home based programs and supervised cardiac rehabilitation were similarly effective in quality of life outcomes for those with heart failure and following myocardial infarction and revascularization [25].

Authors of a third study failed to find differences between clinically supervised exercises and home exercise programs in reducing pain and disability in people with subacromial impingement [26]. In that study, the HEP group had one supervised visit followed by HEP for 6 weeks. The supervised group had 10 supervised exercise visits in addition to HEP for 6 weeks.

There was a study that opposed this current study conclusions and reported superiority of a HEP [27]. Researchers in that study compared a home program ischemic pressure and sustained stretching with active ROM exercises in 40 individuals with neck and upper back myofascial trigger points. They concluded that the home program was more effective in reducing trigger point sensitivity than the clinical group. However, the clinical group did not receive sustained stretching or ischemic compression.
There was one study that showed HEP was not effective in reducing pain, disability or improving flexibility in patients with chronic LBP. However, it had only one group and there was not a comparison group. Therefore, no conclusions could be withdrawn from that study [28].

It may not be argued that drop outs influenced the study findings. Only seven participants withdrew from the study due to some difficulties unrelated to the interventions. No adverse effects were recorded in any of the patients in either group. Patients in the HEP received a consultation after two weeks of treatment and there was no consultation for the following four weeks. This may have the affected the results of this study. Therefore, it is suggested that patients may receive a consultation every other week till end of the intervention program. It may be advised that patients should receive consultations after shorter periods to increase adherence.

The present study had some limitations. Sample size was small and no power analysis was done to determine the appropriate sample size. There is was also lack of long-term follow up. Also, electromyography was not used to assess muscle recruitment during exercises. For further research, researchers should did measure psychologicalorsocial outcomes that may affect exercise performance or adherence. Future studies should involve a large sample size of different patient populations using different home programs. Studies should also include long term follow up to determine whether the improvement in the dependent variables that was observed in this six week follow-up is sustained long-term. Based on the results of the statistical analyses and within the limitations of the study, it can be concluded that clinicallysupervised exercises combined with HEP may be more appropriate than HEPalone in managing patients with chronic LBP.

\section{Competing interests}

The author declares that he has no competing interests.

Publication history

Editor: Mohammad H. Hadadzadeh, Wheeling Jesuit University, USA.

Received: 10-Mar-2017 Final Revised: 23-Jul-2017

Accepted: 14-Aug-2017 Published: 23-Aug-2017

\section{References}

1. Hoy D, Brooks P, Blyth F and Buchbinder R. The Epidemiology of low back pain. Best Pract Res Clin Rheumatol. 2010; 24:769-81. | Article I PubMed

2. Karunanayake AL, Pathmeswaran A, Kasturiratne A and Wijeyaratne LS. Risk factors for chronic low back pain in a sample of suburban Sri Lankan adult males. Int J Rheum Dis. 2013; 16:203-10. | Article | PubMed

3. Metgud DC, Khatri S, Mokashi MG and Saha PN. An ergonomic study of women workers in a woolen textile factory for identification of healthrelated problems. Indian J Occup Environ Med. 2008; 12:14-9. I Article | PubMed Abstract | PubMed FullText

4. Beattie PF, Silfies SP and Jordon M. The evolving role of physical therapists in the long-term management of chronic low back pain: 
Tarek Ammar, Physical Therapy and Rehabilitation 2017,

longitudinal care using assisted self-management strategies. Braz J Phys Ther. 2016; 20:580-591. | Article | PubMed Abstract | PubMed FullText

5. Alp A, Mengi $G$ and Avsaroglu HA et al. Efficiacy of core-stabilization exercise and its comparison with home-based conventional exercise in low back pain patients. Turk J Phys Med Rehab. 2014; 60:36-42. | Pdf

6. Holden MA, Haywood KL, Potia TA, Gee M and McLean S. Recommendations for exercise adherence measures in musculoskeletal settings: a systematic review and consensus meeting (protocol). Syst Rev. 2014; 3:10. | Article | PubMed Abstract | PubMed FullText

7. Kim YW, Kim NY, Chang WH and Lee SC. Comparison of the Therapeutic Effects of a Sling Exercise and a Traditional Stabilizing Exercise for Clinical Lumbar Spinal Instability. J Sport Rehabil. 2016; 1-23. | Article | PubMed

8. Ben Salah Frih Z, Fendri Y, Jellad A, Boudoukhane S and Rejeb N. Efficacy and treatment compliance of a home-based rehabilitation programme for chronic low back pain: a randomized, controlled study. Ann Phys Rehabil Med. 2009; 52:485-96. | Article | PubMed

9. McCaskey MA, Schuster-Amft C, Wirth B, Suica Z and de Bruin ED. Effects of proprioceptive exercises on pain and function in chronic neck- and low back pain rehabilitation: a systematic literature review. BMC Musculoskelet Disord. 2014; 15:382. | Article | PubMed Abstract | PubMed FullText

10. Escolar-Reina P, Medina-Mirapeix F, Gascon-Canovas JJ, MontillaHerrador J, Jimeno-Serrano FJ, de Oliveira Sousa SL, del Bano-Aledo ME and Lomas-Vega R. How do care-provider and home exercise program characteristics affect patient adherence in chronic neck and back pain: a qualitative study. BMC Health Serv Res. 2010; 10:60. | Article | PubMed Abstract | PubMed FullText

11. Hawker GA, Mian S, Kendzerska T and French M. Measures of adult pain: Visual Analog Scale for Pain (VAS Pain), Numeric Rating Scale for Pain (NRS Pain), McGill Pain Questionnaire (MPQ), Short-Form McGill Pain Questionnaire (SF-MPQ), Chronic Pain Grade Scale (CPGS), Short Form-36 Bodily Pain Scale (SF-36 BPS), and Measure of Intermittent and Constant Osteoarthritis Pain (ICOAP). Arthritis Care Res (Hoboken). 2011; 63 Suppl 11:S240-52. | Article | PubMed

12. Vianin M. Psychometric properties and clinical usefulness of the Oswestry Disability Index. J Chiropr Med. 2008; 7:161-3. | Article | PubMed Abstract | PubMed FullText

13. Simmonds MJ, Olson SL, Jones S, Hussein T, Lee CE, Novy D and Radwan H. Psychometric characteristics and clinical usefulness of physical performance tests in patients with low back pain. Spine (Phila Pa 1976). 1998; 23:2412-21. | Article | PubMed

14. Smeets RJ, Hijdra HJ, Kester AD, Hitters MW and Knottnerus JA. The usability of six physical performance tasks in a rehabilitation population with chronic low back pain. Clin Rehabil. 2006; 20:989-97. | Article | PubMed

15. McGill SM. Low back exercises: evidence for improving exercise regimens. Phys Ther. 1998; 78:754-65. I PubMed

16. Ammar T and Mitchell K. Stabilization exercises in postnatal low back pain. Indian J Phy Occupat Th. 2011; 5:122-24. | Article

17. Ammar T. McGill Exercises versus Conventional Exercises in Chronic Low Back Pain. Life Sc J. 2012; 9:393-397. I Pdf

18. Dishman RK. (ed). Advancesinexercise adherence. Champaign, Human Kinetics. 1994.

19. Mannion AF, Helbling D, Pulkovski N and Sprott H. Spinal segmental stabilisation exercises for chronic low back pain: programme adherence and its influence on clinical outcome. Eur Spine J. 2009; 18:1881-91. | Article | PubMed Abstract | PubMed FullText

20. Nava-Bringas TI, Roeniger-Desatnik A, Arellano-Hernandez A and CruzMedina $E$. [Adherence to a stability exercise program in patients with chronic low back pain]. Cir Cir. 2016; 84:384-91. | Article | PubMed

21. Hugli AS, Ernst MJ, Kool J, Rast FM, Rausch-Osthoff AK, Mannig A, Oetiker $\mathrm{S}$ and Bauer $\mathrm{CM}$. Adherence to home exercises in non-specific low back pain. A randomised controlled pilot trial. J Bodyw Mov Ther. 2015; 19:177-85. | Article | PubMed

22. Jordan JL, Holden MA, Mason EE and Foster NE. Interventions to improve adherence to exercise for chronic musculoskeletal pain in adults. Cochrane Database Syst Rev. 2010; CD005956. | Article | PubMed

23. Savage P, Ricci MA, Lynn M, Gardner A, Knight S, Brochu M and Ades $P$. Effects of home versus supervised exercise for patients with intermittent claudication. J Cardiopulm Rehabil. 2001; 21:152-7. | Article I PubMed

24. Florez-Garcia M, Garcia-Perez F, Curbelo R, Perez-Porta I, Nishishinya B, Rosario Lozano MP and Carmona L. Efficacy and safety of home-based exercises versus individualized supervised outpatient physical therapy programs after total knee arthroplasty: a systematic review and metaanalysis. Knee Surg Sports Traumatol Arthrosc. 2016. | Article I PubMed

25. Buckingham SA, Taylor RS, Jolly K, Zawada A, Dean SG, Cowie A, Norton RJ and Dalal HM. Home-based versus centre-based cardiac rehabilitation: abridged Cochrane systematic review and meta-analysis. Open Heart. 2016; 3:e000463. | Article | PubMed Abstract | PubMed FullText

26. Granviken $F$ and Vasseljen $O$. Home exercises and supervised exercises are similarly effective for people with subacromial impingement: a randomised trial. J Physiother. 2015; 61:135-41. | Article | PubMed

27. Hanten WP, Olson SL, Butts NL and Nowicki AL. Effectiveness of a home program of ischemic pressure followed by sustained stretch for treatment of myofascial trigger points. Phys Ther. 2000; 80:997-1003. PubMed

28. Anar SO. The effectiveness of home-based exercise programs for low back pain patients. J Phys Ther Sci. 2016; 28:2727-2730. | Article | PubMed Abstract | PubMed FullText

Citation:

Ammar T. A randomized comparison of supervised clinical exercise versus a home exercise program in patients with chronic low back pain. Phys Ther Rehabil. 2017; 4:7.

http://dx.doi.org/10.7243/2055-2386-4-7 